The Egyptian Journal of Hospital Medicine (October 2018) Vol. 73 (1), Page 5818-5827

\title{
The Predictors of Obstructive Sleep Apnea at A High Altitude: Results of a Population-based Study in the Western region of Saudi Arabia Fahad Rajallah Alharthi ${ }^{1}$, Ibrahim Masoodi ${ }^{1}$, Naif Alomairi ${ }^{1}$, Abdullah Hassan, Almuntashirii ${ }^{1}$, Abdulaziz Alfaifi ${ }^{2}$ \\ 1.Dept of Internal Medicine College of Medicine, Taif University ,2.Dept of Internal Medicine King Abdul Aziz Specialist hospital, Taif ,KSA
}

Corresponding author: Ibrahim Masoodi, Email: ibrahimmasoodi@yahoo.co.in , Phone number : +966531507399

\begin{abstract}
Background: The sleep disturbances are common at high altitudes. This study aimed to determine the prevalence and predictors of obstructive sleep apnea at high altitudes.

Methods: This cross-sectional observational study was conducted from March 2018 to June 2018 to assess the predictors of obstructive sleep apnea based on Berlin, Stop-Bang and Epworth sleepiness scale questionnaire from adult population of Taif City at an altitude of $1879 \mathrm{~m}$ from sea level in Saudi Arabia.

Results: Of 1002 participants, the majority (614 participants, 61.3\%) were males and the mean \pm SD age of participants was 30.6 \pm 10.3 years (Range 11 - 67 years). In this study $24.9 \%$ participants were found to be at a high risk of having sleep apnea. Male gender, older age and smoking were found to be significantly associated with higher risk of sleep apnea according to Berlin, Stop-Bang and Epworth sleepiness scale questionnaire. Diseases found to be associated with a high risk of developing sleep apnea included hypertension $(p<0.001)$, hyperlipidemia $(p<0.001)$, diabetes $(p<0.001)$, psychological disorders $(p<0.001)$ and asthma $(p<0.001)$.On the other hand, cardiac disorders were found to have an insignificant effect on sleep apnea $(\mathrm{p}=0.076)$ in this study. Almost one-third of the participants (34.9\%; $95 \% \mathrm{CI}=32.0 \%$ to $37.9 \%$ ) were found to have an abnormal level of daytime sleepiness according to Epworth Sleepiness Scale (ESS). These results were comparable to the previous studies at low altitude.

Conclusions: Our study demonstrated that the predictors of OSA at high altitudes are comparable to those at low altitudes.
\end{abstract}

Keywords: Daytime sleepiness, Obstructive sleep apnea, prevalence, Diabetes, Hypertension, Asthma.

\section{INTRODUCTION}

Obstructive sleep apnea (OSA) is a common sleep disorder characterized by recurrent upper airway collapse during sleep with frequent awakening and sleep dissolution. When left untreated it significantly increases the risk of cardiovascular diseases, stroke, and death. Consequent to this daytime sleepiness, reduced cognitive performance, OSA increases the risk of motor vehicle accidents and work accidents. It is evident that the early screening to identify the at-risk population of OSA will positively affect the individual in particular and society at large. The prevalence of OSA varies according to the measurement methods, diagnostic criteria, and apnea-hypopnea index (AHI) ${ }^{1}$. While it is prevalent more often in old people, there seems some gender difference as the prevalence in males is $24 \%$ and $9 \%$ in females .However, with an epidemic of obesity, the prevalence of OSA has increased in the last two decades both in developing and developed countries ${ }^{2}$. Possibly due to the craniofacial features among Asians population the data related to OSA is similar in Asian and western countries $^{3}$. Apart from obesity various other factors contributing directly or indirectly are Study participants with resistant hypertension and Study participants with cardiovascular diseases ${ }^{4}$. There is enough data to suggest that there is an association between OSA and certain medical conditions like type 2 diabetes mellitus, coronary heart disease, and polycystic ovary syndrome ${ }^{2}$ Although Polysomnography (PSG) is considered to be the gold standard for diagnosis of OSA in adults but owing to its high cost and limited accessibility, it does not appear to be the universal tool in the detection of Study participants at risk for OSA. Hence screening of Study participants with OSA symptoms, such as snoring, nocturnal gasping, witnessed apnea, etc. and those who have co-morbid conditions related to a high risk of OSA, such as elevated body mass index, smoking, hypertension etc. becomes a plausible tool to screen and for further evaluation in a given population for OSA $^{5}$.

Of various questionnaires available the Berlin questionnaire is the most widely used questionnaire for screening people at high risk of OSA in clinical practice, and its screening properties have been validated in several population-based studies. ${ }^{6}$ The diagnostic performance of the Berlin questionnaire was shown to have a pooled sensitivity of 0.76 and a pooled specificity of 0.45 when predicting OSA with an AHI cutoff of $\geq 5^{7}$. 
Taif City is situated in the western region of Saudi Arabia located at an altitude of $1,879 \mathrm{~m}$ and has a population of around one million. Sleep disturbances are well known at high altitudes In a recent study at Taif University the overall incidence of sleep disorders was found to be $31.33 \%$ leading to excessive day time sleeping among the participants, which correlated to the height of the residence above the sea level ${ }^{8}$.There is a paucity of data related to prevalence and risk factors of OSA secondary to sleep disorders observed in the aforementioned study hence we were prompted to undertake this study in this region based on Berlin, Stop-Bang and Epworth sleepiness scale questionnaire.

\section{MATERIAL AND METHOD Study design:}

This was a cross-sectional observational study conducted to assess the prevalence of OSA and its predictors. One thousand and two people from Taif City, Saudi Arabia participated into the study after an appropriate consent . Taif City is at an altitude of $1879 \mathrm{~m}$ from sea level in the western region of Saudi Arabia. The study was conducted from March 2018 to June 2018 based on Berlin, Stop-Bang and Epworth sleepiness scale questionnaire. The study was conducted in full compliance with the guidelines of the good clinical practice of the world medical assembly declaration of Helsinki. (64th World Medical Association General Assembly, Fortaleza, Brazil, October 2013) and had an ethical approval. The risk factors associated with the occurrence of OSA were also studied.

\section{Statistical considerations}

Data were statistically described regarding frequencies (number of cases) and valid percentages for categorical variables. Mean, standard deviations, minimum and maximum were used to describe numerical variable (median and inter-quartile range (IQR) were considered for nonparametric data). Comparison of categorical variables between the subgroups (crosstabulation) was done using Chi-square test. While the comparison of numerical variables between the subgroups was done using one-way ANOVA test. P values less than 0.05 were considered statistically significant. All statistical calculations were done using computer program IBM SPSS (Statistical Package for the Social Science; IBM Corp, Armonk, NY, USA) release 21 for Microsoft Windows.

\section{Data collection}

There is no available validated Arabic Berlin, StopBang and Epworth sleepiness scale. So that, the questionnaires were correctly translated from English to Arabic and then conducted online. Questionnaire though electronic Google upload form and an excel sheet of the results obtained was further analysed.

\section{Berlin questionnaire (BQ):}

The BQ (incorporates questions about snoring (category 1), daytime somnolence (category 2), and hypertension and BMI (category 3). The BQ was administered at the time of the study subjects initial visit. When available, the participant's family or bed partner was asked to confirm the accuracy of responses to the questions about snoring. The overall BQ score was determined, as in previous studies, from the responses to the three categories: scores from the first and second categories were positive if the responses indicated frequent symptoms (>3-4 times/week), whereas the score from the third category was positive if there was a history of hypertension or a BMI $>30$ $\mathrm{kg} / \mathrm{m}^{2}$. Study participants were scored as being at highrisk for OSA if they had a positive score on two or more categories, while those who did not were scored as being at low-risk ${ }^{9}$.

\section{STOP-Bang questionnaire:}

This has been designed in a simple yes/no format, and the scores range from a value of 0 to 8 . STOPBang questionnaire scores subjects as either "high risk", "intermediate" or "low risk" for OSA. Answering yes to 5-8 questions in STOP-Bang questionnaire is considered "high risk," whereas answering yes to 3-4 questions is considered "intermediate risk" while answering less than two is considered "low risk"

\section{The Epworth Sleepiness Scale:}

This self-administrated questionnaire enquires participants to rate how likely they would have dozed in 8 specific situations or activities commonly met in daily life. The chance of dozing being rated on a scale of $0-3$ ( $0=$ would never dose, $1=$ slight chance of dozing, 2 = moderate chance of dozing, and $3=$ high probability of dozing). The total ESS score is the sum of 8 -items scores and can range between 0 and 24 . The higher the score, the higher the person's level of daytime sleepiness as follows: normal, 0-10; and excessive daytime sleepiness, 11-24. Thus, the ESS final score was categorized into less than 11 (low risk for sleepiness) and more or equal to 11 (high risk for sleepiness) ${ }^{11}$.

\section{RESULTS}

\section{Descriptive Analysis}

\section{- Subjects' characteristics:} $\circ$ Gender

Out of $1002(100 \%)$ participants, the majority (614 participants, $61.3 \%$ ) were males while 388 participants $(38.7 \%)$ were females. 
Fahad Alharthi et al.

\section{$\circ$ Age}

The mean \pm SD age of participants was $30.6 \pm 10.3$ years with a minimum value of 11 and a maximum value of 67 years.

\section{○ Body Mass Index (BMI)}

The mean \pm SD body weight was $73.9 \pm 10.3 \mathrm{~kg}$, and the mean \pm SD height was $166.8 \pm 9.4 \mathrm{~cm}$. Body Mass Index (BMI) was calculated where the mean $\pm \mathrm{SD}$ value was found to be $26.4 \pm 6.4 \mathrm{~kg} / \mathrm{m}^{2}$. The participants were classified into 4 categories based on their BMI including under-weight (BMI $<18.5 \mathrm{~kg} / \mathrm{m}^{2}$ ), normal weight $\left(\mathrm{BMI}=18.5-24.9 \mathrm{~kg} / \mathrm{m}^{2}\right)$, overweight $(\mathrm{BMI}=$ $\left.25-29.9 \mathrm{~kg} / \mathrm{m}^{2}\right)$, and obese $\left(\mathrm{BMI} \geq 30 \mathrm{~kg} / \mathrm{m}^{2}\right)$. The largest category included participants with normal weight (394 participants, 40.5\%). This was followed by over-weight participants (283 participants, 29.1\%), obese participants (231 participants, 23.7\%), and under-weight participants (66 participants, 6.8\%) . 28 study participants failed to arrive for BMI calculations so BMI was calculated in 974 participants.

\section{○ Neck diameter}

The participants were asked about their neck diameter where only $120(12.0 \%)$ answered this question. The mean \pm SD reported value of neck diameter was $30.3 \pm 9.8 \mathrm{~cm}$ with a minimum value of 18 and a maximum value of $67 \mathrm{~cm}$.

\section{○ Smoking status:}

Data on smoking status were collected and the majority, 775 (77.3\%) participants, were non-smokers and $227(22.7 \%)$ participants were smokers. The number of cigarettes smoked per day ranged from 1 to 60 cigarettes/day with a median (IQR) value of 17 (10) cigarettes/ day while the number of smoking years ranged from 1 to 40 years with a median (IQR) value of 7 (8.0) years.

\section{Answers to Berlin questionnaire:}

\section{Category 1 (items 1 to 5):}

The majority $(50.9 \%)$ of participants, said that they don't snore, $34.1 \%$ said that they snore, while $15.0 \%$ of participants said that they don't know. Regarding loudness of snoring, $62.3 \%$ said that their snoring is slightly louder than breathing, $23.5 \%$ said that it is as loud as talking, while $14.2 \%$ said that it is louder than talking. Regarding frequency of snoring, $12.9 \%$ said that they snore almost every day, $8.1 \%$ said that they snore 3 or 4 times per week, $10.4 \%$ said that they snore 1 to 2 times per week, $8.5 \%$ said that they snore 1 to 2 times per month while the majority $(60.2 \%)$ said that they rarely or never snore. Participants were asked if their snoring ever bothered other people and less than one quarter of the participants (23.7\%) said "Yes", $46.9 \%$ said "No" while $29.4 \%$ said that they don't know. When asked if anyone has noticed that they stop breathing during sleeping, $4.8 \%$ said that this occurs almost every day, $2.6 \%$ said that this occurs 3 or 4 times per week, $3.7 \%$ said that this occurs 1 to 2 times per week, $8.8 \%$ said that this occurs 1 to 2 times per month while the majority $(80.1 \%)$ said that this rarely or never occurs. Details are provided in table 1.

Category 2 (items 6 to 9):

Participants were asked how often they feel tired or fatigued after sleeping and $16.4 \%$ said that this occurs almost every day, $12.2 \%$ said that this occurs 3 or 4 times per week, $16.5 \%$ said that this occurs 1 to 2 times per week, $19.7 \%$ said that this occurs 1 to 2 times per month while $35.3 \%$ said that this rarely or never occurs. While upon asking about the frequency of feeling tired, fatigued or not up to par during waking time, $24.1 \%$ said that this occurs almost every day, $16.0 \%$ said that this occurs 3 or 4 times per week, $20.0 \%$ said that this occurs 1 to 2 times per week, $16.5 \%$ said that this occurs 1 to 2 times per month while $23.6 \%$ said that this rarely or never occurs. Almost one third of the participants (32.8\%) said that they have nodded off or fallen asleep while driving a vehicle while two thirds $(67.2 \%)$ said that this didn't happen before. And regarding the frequency, 6.5\% said that this occurs almost every day, $7.2 \%$ said that this occurs 3 or 4 times per week, $5.1 \%$ said that this occurs 1 to 2 times per week, $22.9 \%$ said that this occurs 1 to 2 times per month while $58.3 \%$ said that this rarely or never occurs. (Table 2 )

Category 3 (item 10):

The last question was about having high blood pressure where the majority $(71.8 \%)$ said that they don't have high blood pressure, $8.7 \%$ said that they have high blood pressure while $19.6 \%$ said that they don't know. (Table 3)

Risk of having sleep apnea according to Berlin questionnaire score:

Participants were classified into high risk or low risk based on their responses to the individual items and their overall scores in the symptom categories. Only one quarter of the participants $(24.9 \%$; $95 \% \mathrm{CI}=22.2 \%$ to $27.5 \%$ ) was found to be at a high risk of having sleep apnea according to Berlin questionnaire while three quarters $(75.1 \%)$ were found to be at low risk .

Risk factors related to sleep apnea according to Berlin questionnaire score:

\section{Participants' characteristics}

The characteristics of participants in the high risk group were compared to those in the low risk group. The older age was found to be associated with higher risk of sleep apnea as the mean \pm SD age of participants in the high risk group (35.1 11.4 years) was significantly higher $(\mathrm{p}<0.001)$ than mean \pm SD age of the low risk group (29.2 \pm 9.5 years).

Regarding gender, it was found that the percentage of males with higher risk (29.2\%) was significantly 
higher $(\mathrm{p}<0.001)$ than that of females with higher risk $(18.0 \%)$.

Body mass index was also found to affect the level of risk as the percentage of high risk among normal weight participants $(8.4 \%)$ was significantly lower $(\mathrm{p}<0.001)$ than that among overweight $(19.1 \%)$ and obese participants $(64.5 \%)$.

Moreover, smoking was also found to significantly affect the risk of sleep apnea as the percentage of participants with high risk among smokers (34.8\%) was significantly higher $(\mathrm{p}<0.001)$ than that among non-smokers (21.9\%) (Table 4).

\section{Concomitant diseases}

The participants with concomitant diseases were found to be at a significantly higher $(\mathrm{p}<0.001)$ risk to develop sleep apnea (42.6\%) compared to those without concomitant diseases (16.6\%). Diseases found to be associated with a significantly high risk of developing sleep apnea included hypertension $(\mathrm{p}<0.001), \quad$ hyperlipidemia $\quad(\mathrm{p}<0.001), \quad$ diabetes $(\mathrm{p}<0.001)$, psychological disorders $(\mathrm{p}<0.001)$ and asthma $(p<0.001)$ while on the other hand, cardiac disorders were found to have no significant effect on sleep apnea $(\mathrm{p}=0.076)$ (Table 5).

The general level of daytime sleepiness according to Epworth Sleepiness Scale (ESS):

Using ESS questionnaire, subjects were asked to rate their probability of falling asleep on a scale from 0 to 3 for eight situations that many people experience during the daily life. The scores for the eight questions were summed up to give a total score. A score in the range of " 0 to 9 " was considered to be normal while a score from "10 to 24 " range was considered to indicate abnormal daytime sleepiness (B).

Almost one-third of the participants $(34.9 \%$; $95 \%$ $\mathrm{CI}=32.0 \%$ to $37.9 \%$ ) were found to have an abnormal level of daytime sleepiness according to Epworth Table 1 Answers to Berlin questionnaire (category 1)
Sleepiness Scale (ESS) while two thirds $(65.1 \%)$ were found to have normal daytime sleepiness as shown in table 6.

Risk factors related to abnormal daytime sleepiness:

Participants' characteristics:

The characteristics of participants in the abnormal daytime sleepiness group were compared to those in the normal sleepiness group as shown in the table (4). Age was found to have no effect on daytime sleepiness as the mean $\pm \mathrm{SD}$ age of participants with abnormal sleepiness (30.4 \pm 10.8 years) didn't differ significantly $(\mathrm{p}=0.615)$ from that of participants with normal daytime sleepiness $(30.7 \pm 10.0$ years). The same as age, gender was found to have no significant effect on daytime sleepiness as the percentage of males with abnormal sleepiness (33.6\%) didn't differ significantly $(\mathrm{p}=0.139)$ from that of females with abnormal sleepiness $(37.1 \%)$. The same as age and gender, body mass index was also found to have no significant effect on daytime sleepiness $(p=0.613)$. Moreover, smoking was also found to have no significant effect on daytime sleepiness $(\mathrm{p}=0.073)$.

\section{Concomitant diseases:}

On the other hand, the concomitant disease was found to have a significant adverse effect on daytime sleepiness as participants with concomitant diseases were found to be at a significantly higher $(\mathrm{p}<0.001)$ risk to have abnormal daytime sleepiness (46.1\%) compared to those without concomitant diseases (29.8\%). Diseases found to be associated with a significantly high risk of developing abnormal daytime sleepiness according to ESS score include hypertension $(p<0.001), \quad$ hyperlipidemia $\quad(p=0.013), \quad$ diabetes $(\mathrm{p}<0.001)$, psychological disorders $(\mathrm{p}<0.001)$ and asthma $(p=0.043)$ while on the other hand, cardiac disorders were found to have no significant effect on daytime sleepiness $(\mathrm{p}=0.156)$. Table 7

\begin{tabular}{|l|c|c|c|}
\hline \multirow{2}{*}{ 1. Do you snore? } & Yes & No & Don't know \\
\cline { 2 - 4 } & $34.1 \%$ & $50.9 \%$ & $15.0 \%$ \\
\hline
\end{tabular}

\begin{tabular}{|l|c|c|c|}
\hline \multirow{2}{*}{ 2. Your snoring is: } & $\begin{array}{c}\text { Slightly louder than } \\
\text { breathing }\end{array}$ & As loud as talking & Louder than talking \\
\cline { 2 - 4 } & $62.3 \%$ & $23.5 \%$ & $14.2 \%$ \\
\hline
\end{tabular}

\begin{tabular}{|l|c|c|c|c|c|}
\hline \multirow{2}{*}{ 3. How often do you snore? } & $\begin{array}{c}\text { Almost } \\
\text { every day }\end{array}$ & $\begin{array}{c}\text { 3-4 times } \\
\text { per week }\end{array}$ & $\begin{array}{c}\mathbf{1 - 2} \text { times } \\
\text { per week }\end{array}$ & $\begin{array}{c}\mathbf{1 - 2} \text { times } \\
\text { per month }\end{array}$ & $\begin{array}{c}\text { Rarely or } \\
\text { never }\end{array}$ \\
\cline { 2 - 6 } & $12.9 \%$ & $8.1 \%$ & $10.4 \%$ & $8.5 \%$ & $60.2 \%$ \\
\hline
\end{tabular}

\begin{tabular}{|l|c|c|c|}
\hline 4. Has your snoring ever & Yes & No & Don't Know \\
\cline { 2 - 4 } bothered other people? & $23.7 \%$ & $46.9 \%$ & $29.4 \%$ \\
\hline
\end{tabular}

\begin{tabular}{|l|c|c|c|c|c|}
\hline $\begin{array}{l}\text { 5. Has anyone noticed that you } \\
\text { stop breathing during your } \\
\text { sleep? }\end{array}$ & $\begin{array}{c}\text { Almost } \\
\text { every day }\end{array}$ & $\begin{array}{l}\text { 3-4 times } \\
\text { per week }\end{array}$ & $\begin{array}{c}\mathbf{1 - 2} \text { times } \\
\text { per week }\end{array}$ & $\begin{array}{c}\mathbf{1 - 2} \text { times } \\
\text { per month }\end{array}$ & $\begin{array}{c}\text { Rarely or } \\
\text { never }\end{array}$ \\
\cline { 2 - 6 } & $4.8 \%$ & $2.6 \%$ & $3.7 \%$ & $8.8 \%$ & $80.1 \%$ \\
\hline
\end{tabular}


Table 2 Answers to Berlin questionnaire (category 2)

\begin{tabular}{|c|c|c|c|c|c|}
\hline \multirow{2}{*}{$\begin{array}{l}\text { 6. How often do you feel } \\
\text { tired or fatigued after your } \\
\text { sleep? }\end{array}$} & $\begin{array}{c}\text { Almost } \\
\text { every day }\end{array}$ & \begin{tabular}{|c|} 
3-4 times per \\
week
\end{tabular} & $\begin{array}{l}\text { 1-2 times per } \\
\text { week }\end{array}$ & $\begin{array}{c}\text { 1-2 times per } \\
\text { month }\end{array}$ & $\begin{array}{c}\text { Rarely or } \\
\text { never }\end{array}$ \\
\hline & $16.4 \%$ & $12.2 \%$ & $16.5 \%$ & $19.7 \%$ & $35.3 \%$ \\
\hline \multirow{2}{*}{$\begin{array}{l}\text { 7. During your waking time, } \\
\text { do you feel tired, fatigued or } \\
\text { not up to par? }\end{array}$} & $\begin{array}{c}\text { Almost } \\
\text { every day }\end{array}$ & $\begin{array}{c}\text { 3-4 times per } \\
\text { week }\end{array}$ & $\begin{array}{l}\text { 1-2 times per } \\
\text { week }\end{array}$ & $\begin{array}{c}1-2 \text { times per } \\
\text { month }\end{array}$ & $\begin{array}{c}\text { Rarely or } \\
\text { never }\end{array}$ \\
\hline & $24.1 \%$ & $16.0 \%$ & $20.0 \%$ & $16.5 \%$ & $23.6 \%$ \\
\hline \multirow{2}{*}{$\begin{array}{l}\text { 8. Have you ever nodded off } \\
\text { or fallen asleep while } \\
\text { driving a vehicle? }\end{array}$} & \multicolumn{2}{|r|}{ Yes } & \multicolumn{3}{|c|}{ No } \\
\hline & \multicolumn{2}{|r|}{$32.8 \%$} & \multicolumn{3}{|c|}{$67.2 \%$} \\
\hline
\end{tabular}

\begin{tabular}{|l|c|c|c|c|c|}
\hline \multirow{2}{*}{$\begin{array}{l}\text { 9. How often does this } \\
\text { occur? }\end{array}$} & $\begin{array}{c}\text { Almost } \\
\text { every day }\end{array}$ & $\begin{array}{c}\text { 3-4 times per } \\
\text { week }\end{array}$ & $\begin{array}{c}\text { 1-2 times per } \\
\text { week }\end{array}$ & $\begin{array}{c}\text { 1-2 times per } \\
\text { month }\end{array}$ & $\begin{array}{c}\text { Rarely or } \\
\text { never }\end{array}$ \\
\cline { 2 - 6 } & $6.5 \%$ & $7.2 \%$ & $5.1 \%$ & $22.9 \%$ & $58.3 \%$ \\
\hline
\end{tabular}

Table 3 Answers to Berlin questionnaire (category 3)

\begin{tabular}{|l|c|c|c|}
\hline 10. Do you have high blood & Yes & No & Don't Know \\
\cline { 2 - 4 } pressure? & $8.7 \%$ & $71.8 \%$ & $19.6 \%$ \\
\hline
\end{tabular}

Table 4 Effect of participants' characteristics on developing sleep apnea

\begin{tabular}{|c|c|c|c|}
\hline Age (years) & High risk & Low risk & $P$ value \\
\hline Mean & 35.1 & 29.2 & \multirow{2}{*}{$P<0.001$} \\
\hline Standard deviation & 11.4 & 9.5 & \\
\hline Gender & High risk & Low risk & P value \\
\hline Males & $29.2 \%$ & $70.8 \%$ & \multirow{2}{*}{$P<0.001$} \\
\hline Females & $18.0 \%$ & $82.0 \%$ & \\
\hline
\end{tabular}

\begin{tabular}{|c|c|c|c|}
\hline BMI Category & High risk & Low risk & P value \\
\hline Underweight & $9.1 \%$ & $90.9 \%$ & \multirow{4}{*}{$\mathrm{P}<0.001$} \\
\hline Normal weight & $8.4 \%$ & $91.6 \%$ & \\
\hline Over-weight & $19.1 \%$ & 80.9 & \\
\hline Obese & $64.5 \%$ & $35.5 \%$ & \\
\hline Smoking & High risk & Low risk & P value \\
\hline Yes & $34.8 \%$ & $65.2 \%$ & \multirow{2}{*}{$\mathrm{P}<0.001$} \\
\hline No & $21.9 \%$ & $78.1 \%$ & \\
\hline
\end{tabular}


Table 5 Effect of concomitant diseases on developing sleep apnea

\begin{tabular}{|l|c|c|c|}
\hline Concomitant diseases & High risk & Low risk & \multirow{2}{*}{ P value } \\
\hline Yes & $42.6 \%$ & $57.4 \%$ & \multirow{2}{*}{$\mathrm{P}<0.001$} \\
\hline No & $16.6 \%$ & $83.4 \%$ & \multirow{2}{*}{ P value } \\
\hline Hypertension & High risk & Low risk & \multirow{2}{*}{$\mathrm{P}<0.001$} \\
\hline Yes & $66.7 \%$ & $33.3 \%$ & \\
\hline No & $21.5 \%$ & $78.5 \%$ & \\
\hline
\end{tabular}

\begin{tabular}{|l|c|c|c|}
\hline Hyperlipidemia & High risk & Low risk & P value \\
\hline Yes & $60.7 \%$ & $39.3 \%$ & \multirow{2}{*}{$\mathrm{P}<0.001$} \\
\hline No & $22.5 \%$ & $77.5 \%$ & \\
\hline
\end{tabular}

\begin{tabular}{|l|c|c|c|}
\hline Diabetes & High risk & Low risk & P value \\
\cline { 1 - 3 } Yes & $54.8 \%$ & $45.2 \%$ & \multirow{2}{*}{$\mathrm{P}<0.001$} \\
\hline No & $22.9 \%$ & $77.1 \%$ & \\
\hline
\end{tabular}

\begin{tabular}{|l|c|c|c|}
\hline Psychological disorders & High risk & Low risk & P value \\
\cline { 1 - 3 } Yes & $43.3 \%$ & $56.7 \%$ & \multirow{2}{*}{$\mathrm{P}<0.001$} \\
\hline No & $22.9 \%$ & $77.1 \%$ & \\
\hline
\end{tabular}

\begin{tabular}{|c|c|c|c|}
\hline Asthma & High risk & Low risk & P value \\
\hline Yes & $39.1 \%$ & $60.9 \%$ & \multirow{2}{*}{$\mathrm{P}<0.001$} \\
\hline No & $23.0 \%$ & $77.0 \%$ & \\
\hline Cardiac disorders & High risk & Low risk & P value \\
\hline Yes & $43.8 \%$ & $56.3 \%$ & \multirow{2}{*}{$\mathrm{P}=0.076$} \\
\hline No & $24.5 \%$ & $75.5 \%$ & \\
\hline
\end{tabular}


Table 6 Effect of participants' characteristics on daytime sleepiness according to ESS score

\begin{tabular}{|c|c|c|c|}
\hline Age (years) & Abnormal & Normal & P value \\
\hline Mean & 30.4 & 30.7 & \multirow{2}{*}{$P=0.615$} \\
\hline Standard deviation & 10.8 & 10.0 & \\
\hline Gender & Abnormal & Normal & $P$ value \\
\hline Males & $33.6 \%$ & $66.4 \%$ & \multirow{2}{*}{$\mathrm{P}=0.139$} \\
\hline Females & $37.1 \%$ & $62.9 \%$ & \\
\hline BMI Category & Abnormal & Normal & P value \\
\hline Underweight & $36.4 \%$ & $63.6 \%$ & \multirow{4}{*}{$\mathrm{P}=0.613$} \\
\hline Normal weight & $33.8 \%$ & $66.2 \%$ & \\
\hline Over-weight & $33.6 \%$ & $66.4 \%$ & \\
\hline Obese & $39.0 \%$ & $61.0 \%$ & \\
\hline Smoking & Abnormal & Normal & P value \\
\hline Yes & $39.2 \%$ & $60.8 \%$ & \multirow{2}{*}{$\mathrm{P}=0.073$} \\
\hline No & $33.7 \%$ & $66.3 \%$ & \\
\hline
\end{tabular}

Table 7 Effect of concomitant diseases on developing sleep apnea

\begin{tabular}{|c|c|c|c|}
\hline Concomitant diseases & Abnormal & Normal & P value \\
\hline Yes & $46.1 \%$ & $53.9 \%$ & \multirow{2}{*}{$\mathrm{P}<0.001$} \\
\hline No & $29.8 \%$ & $70.2 \%$ & \\
\hline Hypertension & Abnormal & Normal & P value \\
\hline Yes & $57.3 \%$ & $42.7 \%$ & \multirow{2}{*}{$\mathrm{P}<0.001$} \\
\hline No & $33.1 \%$ & $66.9 \%$ & \\
\hline
\end{tabular}

\begin{tabular}{|c|c|c|c|}
\hline Hyperlipidemia & Abnormal & Normal & P value \\
\hline Yes & $49.2 \%$ & $50.8 \%$ & \multirow{2}{*}{$\mathrm{P}=0.013$} \\
\hline No & $34.0 \%$ & $66.0 \%$ & \\
\hline Diabetes & Abnormal & Normal & P value \\
\hline Yes & $58.1 \%$ & $41.9 \%$ & \multirow{2}{*}{$\mathrm{P}<0.001$} \\
\hline No & $33.4 \%$ & $66.6 \%$ & \\
\hline
\end{tabular}

\begin{tabular}{|l|c|c|c|}
\hline Psychological disorders & Abnormal & Normal & P value \\
\hline Yes & $52.6 \%$ & $47.4 \%$ & \multirow{2}{*}{$\mathrm{P}<0.001$} \\
\hline No & $33.0 \%$ & $67.0 \%$ & \\
\hline
\end{tabular}

\begin{tabular}{|l|c|c|c|}
\hline Asthma & Abnormal & Normal & P value \\
\hline Yes & $42.6 \%$ & $57.4 \%$ & \multirow{2}{*}{$\mathrm{P}=0.043$} \\
\hline No & $33.9 \%$ & $66.1 \%$ & \\
\hline
\end{tabular}

\begin{tabular}{|l|c|c|c|}
\hline Cardiac disorders & Abnormal & Normal & P value \\
\cline { 1 - 3 } Yes & $50 \%$ & $50 \%$ & \multirow{2}{*}{$\mathrm{P}=0.156$} \\
\hline No & $34.7 \%$ & $65.3 \%$ & \\
\hline
\end{tabular}




\section{DISCUSSION}

Our study identified one-quarter of the participants to be at high risk of having sleep apnea according to the Berlin questionnaire. The frequency among adults was higher compared to young people in this study. Most of the study results are in cognizance to our result ${ }^{12,13}$. Nevertheless, a study has observed that sleep disorders may be prevalent among adolescents and young adults, possibly due to factors related to their lifestyle, hormonal and emotional disturbances ${ }^{8}$. Males were significantly at risk of OSA compared to females in our study. The data on 355 Saudi Arabian participants revealed the prevalence of OSA to be higher among males compared to females similar to our results ${ }^{14}$ While our study focused Saudi Arabian population only, Geovanini et al., in a multi-ethnic cohort, concluded that associations were stronger in men, younger individuals, and African Americans ${ }^{15}$.

The obesity was significantly associated with a higher risk of OSA compared to participants with normal weight in this study. In obese individuals, weight reduction together with a healthy diet and increased physical activity may correct or at least improve the symptoms of OSA ${ }^{16}$. It is well known that higher leptin levels are found in OSA Study participants and obese individuals as well. The increased leptin levels are associated with increased platelet aggregation ${ }^{17}$. Having said this, OSA seems to trigger a pro-thrombotic state and impaired glucose tolerance leading to cardiovascular events frequently found in this population. There is increasing evidence suggesting that surrogate markers of cardiovascular risk, including sympathetic activation, systemic inflammation, and endothelial dysfunction, are significantly increased in obese people with OSA versus those without OSA. Intermittent hypoxia is known to exacerbate the metabolic dysfunction of obesity, leading to increased insulin resistance and its consequences.

A higher risk of OSA was found among smokers than in non-smokers in our study which is following various observational study ${ }^{18}$. In one small cross-sectional study, investigators found a smoking prevalence of $35 \%$ in patients with OSA compared with only $18 \%$ in an unmatched group of patients without $\mathrm{OSA}^{19}$. Tobacco and other ingredients in cigarettes cause airway inflammation leading to narrowing and collapse of the upper airways during sleep. In a study by Virkkula et al., among 40 patients referred for nasal surgery for snoring or suspicion of sleep-disordered breathing, smokers tended to be younger than nonsmokers and had greater snoring times and snoring intensities ${ }^{20}$. Even a higher total nasal resistance after decongestion, independent of
OSA severity or BMI has been demonstrated among smokers. Further histological studies have demonstrated an increased thickness and edema of the uvular mucosal lamina propria among smokers compared to non-smokers. Of other mechanisms described in the literature, smoking disrupts sleep architecture and sleep fragmentation in addition to sleep deprivation ${ }^{21}$. All these mechanisms contribute to higher prevalence of OSA among smokers.

Our study demonstrated a significantly higher risk of development of sleep apnea among study participants with hypertension, hyperlipidemia, diabetes, psychological disorders and asthma as shown in the table 5 .

The link between hypertension and OSA is profound, and the consensus guidelines for the management of hypertension emphasizes that OSA must be ruled out before labelling a patient as having idiopathic hypertension as the OSA treatment has been found to control blood pressure in resistant cases ${ }^{22}$.

The people with diabetes had a higher risk of OSA compared to non-diabetic individuals, and various studies have shown that severity of OSA correlates with the degree of insulin resistance. In fact, some studies have revealed a fivefold increase in diabetes among patients with severe $\operatorname{OSA}^{23}$. The OSA risk in people with diabetes increases with age and is irrespective whether the patient is managed with oral hypoglycemic drugs or insulin. The OSA may augment pro-thrombotic state in diabetes hence people with diabetes must be screened for this disorder. While the leptin levels are shown to decrease with OSA treatment and hence the pro-thrombotic state, the glucose tolerance does not improve with OSA management ${ }^{24}$. OSA is independently associated with increased glucose and triglyceride levels as well as markers of inflammation, arterial stiffness, and atherosclerosis. This observation implies that effective treatment of OSA with continuous positive airway pressure for three months significantly have been found to lead the reduction of blood pressure, triglyceride levels, and visceral fat ${ }^{25}$.

In accordance to our study a systematic review suggests that there is a high prevalence of OSA in asthma, particularly in patients with severe asthma the co-diagnosis of OSA is associated with worse clinical outcomes $^{26 .}$

Higher risk of OSA was observed among participants with psychological disorders. OSA affects microcirculation of the brain and causes blood brain barrier dysfunction resulting in the development or exacerbation of depressive symptoms and cognitive deficits. This phenomenon may be highly relevant among elderly people with already compromised 
cerebral circulation. Thus it is essential to screen individuals at high risk of OSA when assessing patients with depressive disorders as OSA treatment may ameliorate depressive symptoms as well ${ }^{27}$.

It was interesting to note that the study participants with hypertension, dyslipidemia, diabetes and psychological disorders were predisposed to abnormal daytime sleepiness as shown in the table 2 cautioning the adverse outcomes, especially while driving in Study participants with these disorders.

Recognition and management of OSA are crucially important. In a nonrandomized study, Dorkova et al. showed that continuous positive airway pressure (CPAP) therapy reduced several components of the metabolic syndrome in patients who used CPAP for $\geq 4 \mathrm{~h} /$ night for 8 weeks, including blood pressure, triglyceride levels, and glucose levels, compared with patients with low adherence to CPAP $(<4 \mathrm{~h} /$ night $){ }^{28}$. As full polysomnography may not be readily available at all centers, portable monitoring ${ }^{29}$ and new technologies for diagnosing $\mathrm{OSA}^{30}$ are promising options in high-risk groups.

We compared our results to the previous studies at Jeddah Saudi Arabia being $21 \mathrm{~m}$ from sea level by Wali et $\mathrm{al}^{3}$. It was observed that despite $34.9 \%$ participants complained of sleep disturbances in our study at high altitude (Taif, $1879 \mathrm{~m}$ ) the predictors of OSA in a given population continue to be same and high altitude doesn't impose an additional risk.

To conclude the results of our study affirm that patients with diabetes, dyslipidemia, asthma, hypertension and obesity must be screened for OSA to prevent the consequences of OSA. There is a need to increase the awareness of OSA in general population and among medical fraternity to prevent the corollary of this disorder which by no means should be underestimated in a given population.

\section{CONFLICT OF INTEREST}

There are no conflicts of interest

\section{ACKNOWLEDGMENTS}

We extend our sincere thanks to following data collectors of this study 1. Majed Saud Aljuaeed 2. Saud Abdul Aziz Ali AlGhamdi, 3. Al Hanouf Abed Salim and 4. Samar Musarri Alkhaldi

\section{REFERENCES}

1.Sunwoo JS, Hwangbo Y, Kim WJ et al.(2018):Prevalence, sleep characteristics, and comorbidities in a population at high risk for obstructive sleep apnea: A nationwide questionnaire study in South Korea. PLoS One, 28:13(2)
2.Kalakattawi RMN, Kalakattawi AMN, Alsuqati FA et al.(2018):Risk of Obstructive Sleep Apnea Assessment Among Study participantsWith Type 2 Diabetes in Taif, Saudi Arabia. J Clin Med Res., 9(12):1002-1006.

3. Wali SO, Abalkhail B et al.(2017): Prevalence and risk factors of obstructive sleep apnea syndrome in a Saudi Arabian population. Ann Thorac Med., 12(2):88-94.

4.Costa LE1, Uchôa CH1, Harmon RR1, Bortolotto LA et al.(2015): Potential underdiagnosis of obstructive sleep apnoea in the cardiology outpatient setting. Heart, 101(16):1288-92.

5. Epstein LJ1, Kristo D, Strollo PJ Jr, Friedman N et al.(2009): Clinical guideline for the evaluation, management and long-term care of obstructive sleep apnea in adults. J Clin Sleep Med., 5(3):263-76.

6. Ahmadi N, Chung SA et al.(2015): The Berlin questionnaire for sleep apnea in a sleep clinic population: relationship to polysomnographic measurement of respiratory disturbance. Sleep Breath, 12(1):39-45.

7. Kapur VK, Auckley DH, Chowdhuri S et al.(2017): Clinical Practice Guideline for Diagnostic Testing for Adult Obstructive Sleep Apnea: An American Academy of Sleep Medicine Clinical Practice Guideline. J Clin Sleep Med., 13(3):479-504.

8. Kabel AM, Al Thumali AM, Aldowiala KA et al.(2018): Sleep disorders in a sample of students in Taif University, Saudi Arabia: The role of obesity, insulin resistance, anemia and high altitude. Diabetes Metab Syndr., 12(4):549-554

9. Netzer NC, Stoohs RA, Netzer CM et al.(1999): Using the Berlin Questionnaire to identify Study participants at risk for the sleep apnea syndrome. Ann Intern Med., 131(7):48591.

10. F. Chung, B. Yegneswaran, P. Liao et al.(2008): STOP questionnaire. A tool to screen Study participants for obstructive sleep apnea. Anesthesiology., 108(2008):812821.

11. M.W. Johns (1994): Sleepiness in different situations measured by the Epworth Sleepiness Scale. Sleep., 17(8):703-710.

12. Phillips B, Cook Y, Schmitt F et al.(1989): Sleep apnea: prevalence of risk factors in a general population. South Med J., 82(9):1090-2.

13. Enright PL, Newman AB, Wahl PW et al.(1996): Prevalence and correlates of snoring and observed apneas in 5,201 older adults. Sleep, 19(7):531-8.

14.Wali SO, Alkhouli A, Howladar M, Ahmad I et al.(2015): Risk of obstructive sleep apnea among Saudis with chronic renal failure on hemodialysis. Ann Thorac Med., 10(4):263-8.

15. Geovanini GR, Wang $\mathrm{R}$, Weng $\mathrm{J}$ et al.(2018): Association between Obstructive Sleep Apnea and Cardiovascular Risk Factors-Variation By Age, Sex and Race: The Multi-Ethnic Study of Atherosclerosis (MESA). Ann Am Thorac Soc., 15(8):970-977.

16. Dobrosielski DA, Patil S, Schwartz AR et al.(2015): Effects of exercise and weight loss in older adults with obstructive sleep apnea. Med Sci Sports Exerc., 47(1):20-6. 
17. Sanner BM, Konermann M, Tepel $M$ et al.(2000): Platelet function in Study participants with obstructive sleep apnoea syndrome. Eur Respir J., 16(4):648-652.

18. Lin YN, Li QY et al.(2012): Interaction between smoking and obstructive sleep apnea: not just participants. Chin Med J (Engl), 125(17):3150-6.

19. Kashyap R, Hock LM et al.(2001): Higher prevalence of smoking in Study participants diagnosed as having obstructive sleep apnea. Sleep Breath, 5(4):167-172.

20. Virkkula P, Hytönen M, Bachour A et al.(2007): Smoking and improvement after nasal surgery in snoring men. Am J Rhinol., 21(2):169-173.

21. Sériès F, Roy $\mathrm{N}$ et al.(1994): Effects of sleep deprivation and sleep fragmentation on upper airway collapsibility in normal subjects. Am J Respir Crit Care Med., 150(2):481-485.

22. Logan AG, Tkacova R, Perlikowski SM et al.(2003): Re- fractory hypertension and sleep apnoea: effect of CPAP on blood pressure and baroreflex. Eur Respir J., 21(2):241247

23. Elmasry A, Lindberg E, Berne C et al.(2001): Sleepdisordered breathing and glucose metabolism in hypertensive men: a population-based study. J Intern Med., 249(2):153-161.

24. Punjabi NM, Ahmed MM, Polotsky VY et al.(2003): Sleep-disordered breathing, glu- cose intolerance, and insulin resistance. Respir Physiol Neurobiol., 136(2-3):167178.

25. Sharma SK, Agrawal S, Damodaran D et al .(2011):CPAP for the metabolic syndrome in patients with obstructive sleep apnea. N Engl J Med., 365(24):2277-86.

26.Davies SE, Bishopp A, Wharton $S$ et al.(2018):The association between asthma and obstructive sleep apnea (OSA): A systematic review. J Asthma, 11:1-12.

27. Hobzova M, Prasko J, Vanek J et al.(2017): Depression and obstructive sleep apnea. Neuro Endocrinol Lett., 38(5):343-352.

28.Dorkova Z, Petrasova D, Molcanyiova A et al.(2008): Effects of continuous positive airway pressure on cardiovascular risk profile in Study participants with severe obstructive sleep apnea and metabolic syndrome. Chest, 134(4):686-92

29. Collop NA, Anderson WM, Boehlecke B et al.(2007): Portable Monitoring Task Force of the American Academy of Sleep Medicine. Clinical guidelines for the use of unattended portable monitors in the diagnosis of obstructive sleep apnea in adult patients. Portable Monitoring Task Force of the American Academy of Sleep Medicine. J Clin Sleep Med., 3(7):737-47

30. Collop NA, Tracy SL, Kapur V et al.(2011): Obstructive sleep apnea devices for out-of-center (OOC) testing: technology evaluation. J Clin Sleep Med., 7(5):53148. 